\title{
Factors Influencing Onset of Habit and Non-Habit Related Oral Squamous Cell Carcinoma
}

\section{Chithralekha B' ${ }^{1}$, Gheena S², Madhulaxmi Marimuthu³}

Section: Healthcare

Sci. Journal Impact

Factor: $6.1(2018)$

ICV: 90.90 (2018)

(c) (i) (8)

Copyright@IJCRR

\begin{abstract}
Saveetha Dental College, Saveetha University of Medical and Technical Science (SIMATS), Saveetha University, Chennai-6ooo77, lndia; ${ }^{2}$ Associate Professor, Department of Oral Pathology, Saveetha Dental College and Hospitals, Saveetha University of Medical and Technical

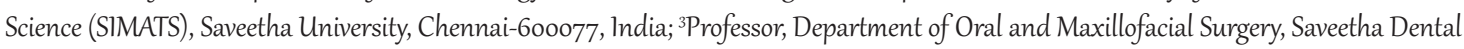
College and Hospitals, Saveetha University of Medical and Technical Science (SIMATS), Saveetha University, 162, PH Road, Chennai-6ooo77, Tamil Nadu, India.
\end{abstract}

\section{ABSTRACT}

Introduction: Oral cancer results due to the persistence of potentially malignant disorders (PMD) over a chronic duration. It is the sixth most common cancer prevailing all over the world. The incidence of oral cancer in Asians has been reported to be very high due to various personal habits and poor knowledge about the occurrence and consequences if diagnosed with a deadly disease such as oral cancer. In the study, all the possible causes for occurrences of oral cancer have been extensively discussed and the study has also tried to investigate the possible underlying reasons behind the occurrence of the disease in a select population namely non-habit-related Oral Squamous Cell Carcinoma (OSCC).

Aim: The aim of the study was to evaluate the diet and other habits affecting non-habit oral cancer patients.

Materials and Methods: The study was performed in a university setting. The study reviewed patient records and analyzed the data of 86000 patients between June 2019 and March 2020. The collected data were compiled and tabulated using Microsoft Excel. The tabulated data were then reviewed and then exported to the SPSS platform for performing statistical analysis.

Results and Discussion: The study has taken a total of six parameters. Of them, only one parameter showed statistical significance and the $p$-value was found to be $0.0001(p<0.005)$. It is also important to note that while the other parameters did not exhibit any sort of statistical significance, all the parameters considered were found to be of paramount clinical significance. Within the confines of the study conducted, we have found out that factors such as chronic irritation, ulcers, sharp tooth, and diet does have a significant role in causing oral cancer.

Key Words: Oral cancer, Diet, Other habits, Personal habits, Pan chewing, Smoking

\section{INTRODUCTION}

Oral cancer has been reported as the third most common cancer in India. ${ }^{1}$ It has been reported that the occurrence and progress of oral cancer in India has been influenced by the cumulative effect of various genetic, environmental, and age factors of the population..$^{2-7}$ The reasons behind the high significance of oral cancer are in most of the cases the diagnosis of oral cancer happens in a very late stage, because a strict dental check-up at least once in a year pattern is not followed in India. ${ }^{8-9}$

Another reason is even if the patient gets to know in an early stage, the socio-economic status of the patient might not allow them to undergo proper treatment due to the financial burden since India is still a developing country. ${ }^{10-11}$ Also, it has been proved that oral cancer detection in an early stage has a possible effect on the treatment outcome and in improving the quality of the patient's life post-treatment. ${ }^{12-18} \mathrm{~A}$ significant relation has been reported between the people of lower socioeconomic status of the society and OSCC since their exposure to tobacco usage has been reported to be very high when compared to socioeconomically stable class. ${ }^{19}$

Few other studies have disclosed that out of all head and neck cancer thirty percent of it is occupied by tongue cancer. And in that $85 \%$ of it occurs in the lateral aspect of the tongue. This set forth an explanation towards why in our study we had observed the tongue as a common site. ${ }^{20}$ Results have been set forth about the variations in the site of occurrence due to geographic distribution, socioeconomic conditions, and rate of occurrence. ${ }^{21-24}$

\section{Corresponding Author:}

Madhulaxmi Marimuthu, Professor, Department of Oral and Maxillofacial Surgery, Saveetha Dental College and Hospitals, Saveetha University of Medical and Technical Science (SIMATS), Saveetha University, 162, PH Road, Chennai-600077, Tamil Nadu, India; Ph:+91 7373814000; Email: madhulaxmi.sdc@gmail.com

ISSN: 2231-2196 (Print)

Received: 14.09 .2020
ISSN: $0975-5241$ (Online)

Revised: 17.10 .2020
Accepted: 12.11 .2020
Published: 26.12 .2020 


\section{MATERIALS AND METHODS}

The study was conducted in a university setting and the ethical number is SDC/SIHEC/2020/DIASDATA/0619-0320. Being done with the entries of one university the advantages regarding the study were that the data were already available and the data belonged to individuals with similar ethnicity. The limitations of the study were geographic limitations, locations, and also the trends of other locations were not assessed.

The study was a retrospective cross-sectional study and the data were collected within a time period of June 2019 to March 2020. There were two reviewers for the study. Ethical approval was provided by the University ethical committee. Case sheets were reviewed and cross-verifications were done. A total of 30 case sheets were taken which has been confirmed with OSCC.

\section{STATISTICAL ANALYSIS}

The data was tabulated by using Microsoft Excel software. It was then exported to SPSS for statistical analysis. The analysis was conducted by the Chi-square test.

\section{RESULTS AND DISCUSSION}

From the study, we found that a small portion of individuals who are diagnosed with oral cancer every year is reported to be devoid of any particular oral habits.

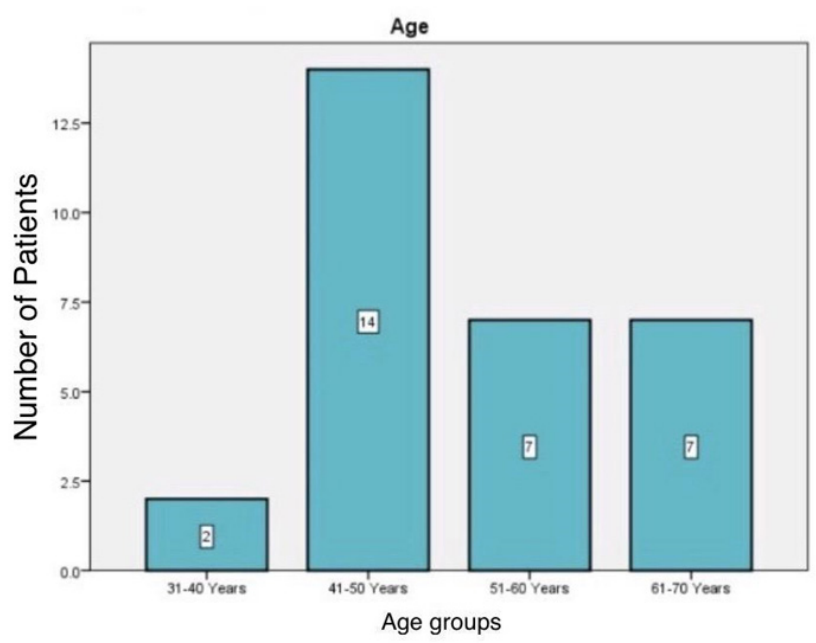

Figure 1: The graph depicts the distribution of age group and OSCC. $\mathrm{X}$-axis shows the age group, $\mathrm{Y}$-axis shows the number of patients affected. Chi-square test was done and the association is statistically not significant $(p$-value $=0.4852, p>0.05$ ) though the most prevalent age group with OSCC was found to be 41-50 years.

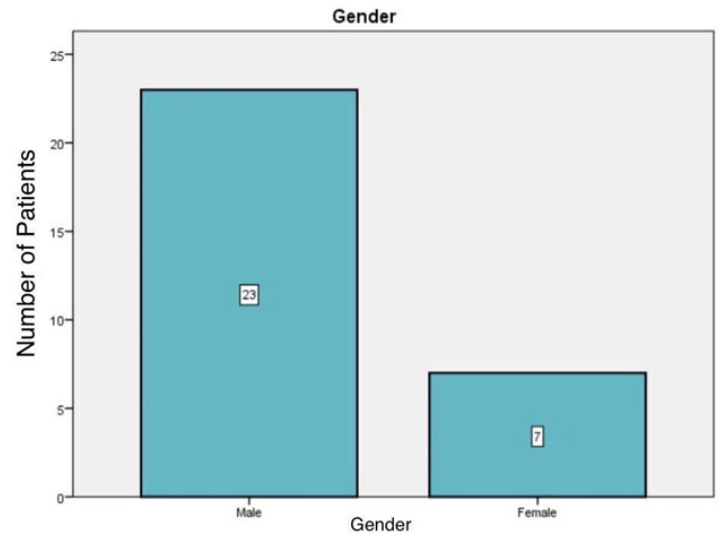

Figure 2: The distribution of gender with respect to the number of patients. $\mathrm{X}$-axis represents the gender and $\mathrm{Y}$-axis represents the number of patients. A male predominance is seen when compared to the female population in the occurrence of OSCC.

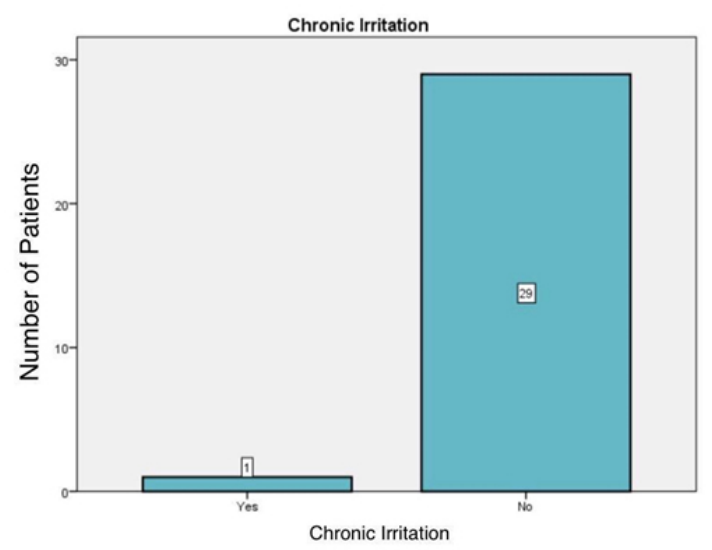

Figure 3: The distribution of chronic irritation with the number of patients. X-axis shows the presence or absence of chronic irritation, Y-axis shows the number of patients. The majority of the patients reported to be devoid of chronic irritation with only one patient reported to have chronic irritation.

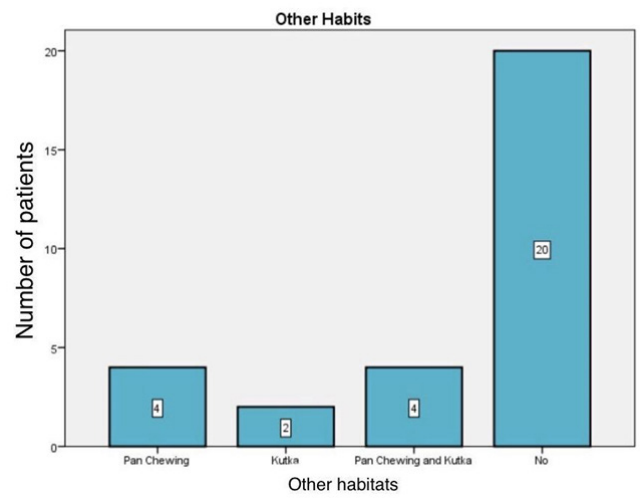

Figure 4: The distribution of other habits and the number of patients. X-axis shows the distribution of other habits like pan, kutka, etc and $Y$-axis represents the number of patients. The maximum number of patients did not have any of these habits, and only 2 patients were reported to have a history of kutka. 


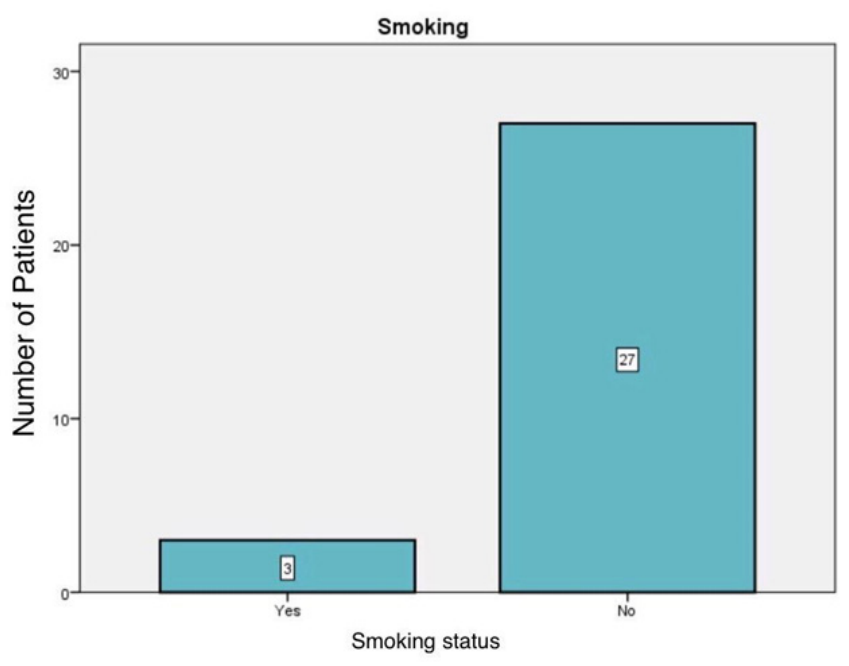

Figure 5: The distribution of smoking status and number of patients. X-axis represents the smoking status and $\mathrm{Y}$-axis represents the number of patients. The majority of the populations were non-smokers.

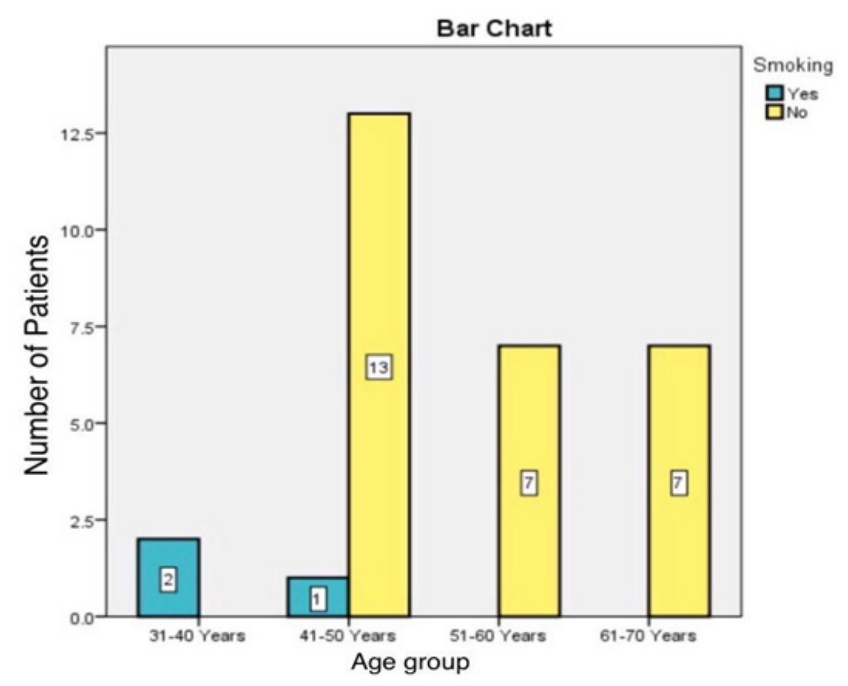

Figure 6: The association between age group and the number of patients with smoking status; Yes (blue) and No (yellow). $\mathrm{X}$-axis represents the age group and $\mathrm{Y}$-axis represents the number of patients. Chi-square test was done, Pearson Chisquare value: $19.683, \mathrm{DF}: 3, \mathrm{p}$-value $=0.0001, \mathrm{p}<0.05$; statistically significant. The maximum number of patients found to be with smoking habits belonged to the age group of 31 to 40 .

From the results obtained in the study, the most affected age group was 41 to 50 , followed by 51 to 60,61 to 70 and the least affected age group was 31 to 40 (Figure 1). It has been supported by Randhawana et al. ${ }^{33}$ that the most affected age group was 41 to 50 . Also, few authors have suggested that the occurrence is very rare under forty years of age. ${ }^{34,35}$ The reasons behind the age group of occurrence of oral cancer being forty to fifty are cited as the smoking and alcohol habits that the patients have developed from a very young age. ${ }^{35-38}$

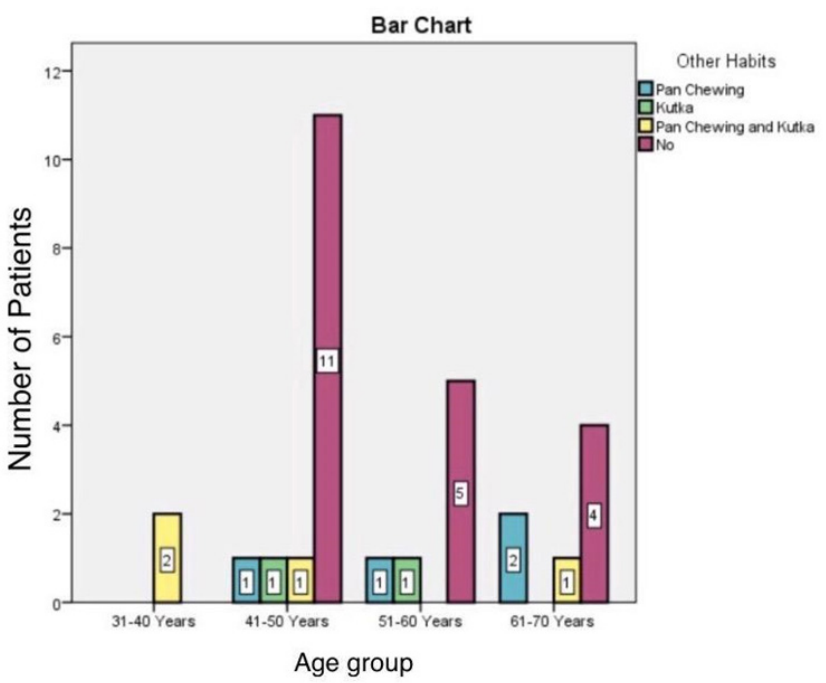

Figure 7: The association between age groups with the number of patients with other habits like pan, kutka, etc; pan chewing (blue), kutka (green), pan chewing, and kutka (yellow), no habits (grape vine). X-axis shows the age group and $\mathrm{Y}$-axis the number of patients. Chi-square test was done, Pearson Chisquare value: 17.464 , DF: $9, p$-value $=0.48, p>0.05$, hence statistically not significant. Though, the maximum number of patients without habits were found to be within the age group of 41 to 50 ; the maximum number of patients with pan chewing and Kutkha habits were found to be within 31-40 yr age group, it was not significantly different across age groups.

A very high male predilection was observed for being presented with OSCC (Figure 2) and considering the other factors, we can come to the conclusion that in India tobacco, pan, and gutka use is predominantly seen in the male population.

In the present study, only a very small percentage of the population did not have any habit histories like smoking or pan chewing or quid or alcohol use. They were reported with chronic irritation or ulcers that were present for almost a year or more (Figure 3).

Tobacco chewing, pan chewing, use of betel nut, or quid has been a part of tradition among different cultural groups all over Asia. In the study, we found that 10 patients, that is $33 \%$ of the total population reported being with pan and kutka chewing habits (Figure 4). Many studies have suggested that persons with these habits are relatively more prone to be diagnosed with oral cancer. ${ }^{25,26}$ Some studies have reported a male-female ratio to be $10: 1 .^{27,28}$ The male-female ratio was found to be $0.92: 1$ in a Malaysian study as well as in a few 
other studies. ${ }^{29,30}$ There have also been studies that have reported no significant gender predominance as well. ${ }^{31,32}$

The habit induced cancer is seen in men more than in women, and in these habits, the smoking status in the population which was only seen in men was found to be statistically significant in the age group of 31 to 40 (p-value for smoking status $=0.0001, \mathrm{p}<0.05$ ).

Another interesting fact that was found is that all the patients in our study were non-vegetarians. Although we could not analyze the type of meat or other factors, it is very evident a non-vegetarian habit might have a very strong correlation with the health status of the patient. There have been researches done in the past that gave hints on these factors like chronic irritation, malnutrition, viral infection, etc. ${ }^{39-41}$

\section{CONCLUSION}

In general, the majority of patients diagnosed with oral cancer were found to be associated with predisposing habits such as tobacco chewing, smoking, gutka, quid, alcohol, etc., with a noticeable predilection for the occurrence of malignancy in the 31-40 yrs age group associated with the smoking habit $(p<0.05)$. The study conducted has brought to our notice that oral cancer is also diagnosed in a noticeable group of patients who were devoid of any predisposing habits such as the ones mentioned above focusing on the fact that diet is also a contributing factor in causing oral cancer as all of the oral cancer patients in our study population followed a non-vegetarian diet. The occurrence of oral cancer in the newer generation is likely due to the lifestyle they lead, the potentially harmful food habits they follow, and lack of knowledge regarding the symptoms and seriousness of the disease. Therefore the medical community should take pre-emptive measures to tackle the occurrence of oral cancer among people and should take initiative to spread knowledge and create awareness among people across all the spectrums of society.

\section{Conflict of Interest}

The authors have no conflict of interest

\section{Funding}

The authors did not receive any funds for this study.

\section{Author Contributions}

Author 1 (Chithralekha B), carried out the retrospective study by collecting data and drafted the manuscript after performing the necessary statistical analysis. Author 2 (Dr. Gheena S) aided in the conception of the topic, has participated in the study design, statistical analysis, and has supervised in preparation of the manuscript. Author 3 (Dr. Madhulaxmi M) has participated in the study design and has coordinated in developing the manuscript. All the authors have discussed the results among themselves and contributed to the final manuscript.

\section{REFERENCES}

1. Francis D. Trends in incidence of head and neck cancers in India. Eur J Cancer 2018;92: S23.

2. Kumar A, Popli G, Bhat S, Mohan S, Sowdepalli A, Kumari K. Oral cancer incidence trends in Delhi (1990-2014): An alarming scenario. South Asian J Cancer 2019;8(2):116-9.

3. Gupta V, Ramani P. Histologic and immunohistochemical evaluation of mirror image biopsies in oral squamous cell carcinoma. Journal of Oral Biology and Craniofacial Research 2016;6:1947.

4. Thangaraj SV, Shyamsundar V, Krishnamurthy A, Ramani P, Ganesan K, Muthuswami M, et al. Molecular Portrait of Oral Tongue Squamous Cell Carcinoma Shown by Integrative MetaAnalysis of Expression Profiles with Validations. PLoS One 2016;11(6):e0156582.

5. Shree KH, Ramani P, Sherlin H, Sukumaran G, Jeyaraj G, Don $\mathrm{KR}$, et al. Saliva as a diagnostic tool in oral squamous cell carcinoma--a systematic review with Meta analysis. Pathol Oncol Res 2019;25(2):447-53.

6. Viveka TS, Shyamsundar V, Krishnamurthy A, Ramani P, Ramshankar V. p53 Expression Helps Identify High Risk Oral Tongue Premalignant Lesions and Correlates with Patterns of Invasive Tumour Front and Tumour Depth in Oral Tongue Squamous Cell Carcinoma Cases. Asian Pacific Journal of Cancer Prevention 2016;17:189-95.

7. Jayaraj G, Sherlin HJ, Ramani P, Premkumar P, Natesan A. Stromal myofibroblasts in oral squamous cell carcinoma and potentially malignant disorders. Indian J Cancer 2015;52(1):87-92.

8. Chakraborthy A, Ramani P, Sherlin HJ, Premkumar P, Natesan A. Antioxidant and pro-oxidant activity of Vitamin $\mathrm{C}$ in oral environment. Indian J Dent Res 2014;25(4):499-504.

9. Premkumar J, Ramani P, Chandrasekar T, Natesan A, Premkumar P. Detection of species diversity in oral candida colonization and anti-fungal susceptibility among non-oral habit adult diabetic patients. J Nat Sci Biol Med 2014;5(1):148-54.

10. Fernández A, Córdova P, Badenier O, Esguep A. Epidemiological characterization of oral cancer. Literature review. Journal Oral of Research 2015;4:137-45.

11. Kumar S, Heller RF, Pandey U, Agarwal GG, Misra RP. Factors causing delay in reporting by oral cancer patients in India. Journal of Clinical Epidemiology 1997;50:S6.

12. World Health Organization. International Classification of Diseases for Oncology: ICD-O. World Health Organization. 2013:242 p.

13. Jangid K, Alexander AJ, Jayakumar ND, Varghese S, Ramani P. Ankyloglossia with cleft lip: A rare case report. J Indian Soc Periodontol 2015;19(6):690-3.

14. Jayaraj G, Ramani P, Sherlin HJ, Premkumar P, Anuja N. Inter-observer agreement in grading oral epithelial dysplasia--a systematic review. Journal of Oral and Maxillofacial Surgery, Medicine and Pathology 2015;27(1):112-6.

15. Sridharan G, Ramani P, Patankar S, Vijayaraghavan R. Evaluation of salivary metabolomics in oral leukoplakia and oral squamous cell carcinoma. J Oral Pathol Med 2019;48(4):299-306.

16. Swathy S, Gheena S, Varsha SL. Prevalence of pulp stones in patients with history of cardiac diseases. Research Journal of Pharmacy and Technology 2015;8(12):1625-8.

17. Kumar A, Sherlin HJ, Ramani P, Natesan A, Premkumar P, Oth- 
ers. Expression of CD 68, CD 45 and human leukocyte antigenDR in central and peripheral giant cell granuloma, giant cell tumor of long bones, and tuberculous granuloma: An immunohistochemical study. Indian J Dent Res 2015;26(3):295.

18. Gheena S, Ezhilarasan D. Syringic acid triggers reactive oxygen species-mediated cytotoxicity in HepG2 cells. Hum Exp Toxicol 2019;38(6):694-702.

19. Conway DI, Petticrew M, Marlborough H, Berthiller J, Hashibe M, Macpherson LMD. Socioeconomic inequalities and oral cancer risk: A systematic review and meta-analysis of case-control studies. International Journal of Cancer 2008;122:2811-9.

20. Watkinson J, Gilbert R. Stell \& Maran's Textbook of Head and Neck Surgery and Oncology 2011.

21. Mummudi N, Agarwal JP, Chatterjee S, Mallick I, Ghosh-Laskar S. Oral Cavity Cancer in the Indian Subcontinent - Challenges and Opportunities. Clinical Oncology 2019;31:520-8.

22. Priyanka S, Department of Pathology, SMS Medical College, Jaipur, Rajasthan, India. A study of Clinico-pathological Spectrum of Oral Cavity Lesions at a Tertiary Care Hospital. Journal of Medical Science And clinical Research 2018;6

23. Sridharan G, Ramani P, Patankar S. Serum metabolomics in oral leukoplakia and oral squamous cell carcinoma. J Cancer Res Ther 2017;13(3):556-61.

24. Kumar MDA, Gheena S. Incidence of dry socket after third molar extraction. Res J Pharm Biol Chem Sci 2015;7(7):451.

25. Takagi M, Kayano T, Yamamoto H, Shibuya H, Hoshina M, Shioda S, et al. Causes of oral tongue cancer treatment failures: Analysis of autopsy cases. Cancer 2010;69:1081-7.

26. Maciuszonek M, Grodecka J, Zielinska-Kazmierska B. P.206 Malignant tumours of the tongue. Journal of Cranio-Maxillofacial Surgery 2006;34:185.

27. Lee J-J, Hung H-C, Cheng S-J, Chen Y-J, Chiang C-P, Liu B-Y, et al. Carcinoma and dysplasia in oral leukoplakias in Taiwan: prevalence and risk factors. Oral Surg Oral Med Oral Pathol Oral Radiol Endod 2006;101(4):472-80.

28. Speight PM, Farthing PM. The pathology of oral cancer. British Dental Journal 2018;225:841-7.

29. Dhanuthai K, Rojanawatsirivej S, Subarnbhesaj A, Thosaporn W, Kintarak S. A multicenter study of oral malignant tumors from Thailand. J Oral Maxillofac Pathol 2016;20(3):462-6.

30. Kruaysawat W, Aekplakorn W, Chapman RS. Survival time and prognostic factors of oral cancer in Ubon Ratchathani Cancer Center. J Med Assoc Thai 2010;93(3):278-84.
31. Shaw RJ, Pace-Balzan A, Butterworth C. Contemporary clinical management of oral squamous cell carcinoma. Periodontology 2000 2011;57:89-101.

32. Dimba EAO, Gichana J, Limo AK, Wakoli KA, Chindia ML, Awange DO. An audit of oral diseases at a Nairobi centre, 20002004. International Dental Journal 2007;57:439-44.

33. Randhawa T, Shameena PM, Sudha S, Nair RG. Squamous cell carcinoma of tongue in a 19-year-old female. Indian Journal of Cancer 2008;45:128.

34. Gaddikeri K, Bhorgonde DD. Oral Squamous Cell Carcinoma of Tongue in a Young Patient - A Rare Case Report and Review of Literature. Annals of International medical and Dental Research 2016;3.

35. Kaminagakura E, Vartanian JG, Silva SD, Kowalski LP. O67. Case control study on prognostic factors in oral squamous cell carcinoma in young patients. Oral Oncology Supplement 2009;3:78-9.

36. Pelucchi C, Gallus S, Garavello W, Bosetti C, La Vecchia C. Cancer risk associated with alcohol and tobacco use: focus on upper aero-digestive tract and liver. Alcohol Res Health 2006;29(3):193-8.

37. Marttila E, Uittamo J, Rusanen P, Lindqvist C, Salaspuro M, Rautemaa R. Acetaldehyde production and microbial colonization in oral squamous cell carcinoma and oral lichenoid disease. Oral Surg Oral Med Oral Pathol Oral Radiol 2013;116(1):61-8.

38. Feller L, Chandran R, Khammissa RAG, Meyerov R, Lemmer J. Alcohol and oral squamous cell carcinoma. SADJ 2013;68(4):176-80.

39. Mehanna H, Paleri V, West CML, Nutting C. Head and neck cancer--Part 1: Epidemiology, presentation and prevention. BMJ 2010;341:c4684.

40. Perry BJ, Zammit AP, Lewandowski AW, Bashford JJ, Dragovic AS, Perry EJ, et al. Sites of Origin of Oral Cavity Cancer in Nonsmokers vs Smokers. JAMA Otolaryngology-Head \& Neck Surgery 2015;141:5.

41. Gillison ML, Castellsagué X, Chaturvedi A, Goodman MT, Snijders P, Tommasino M, et al. Eurogin Roadmap: Comparative epidemiology of HPV infection and associated cancers of the head and neck and cervix. International Journal of Cancer 2014;134:497-507. 